\title{
Does growth hormone supplementation improve oocyte competence and IVF outcomes in patients with poor embryonic development? A randomized controlled trial
}

Jingyu Li, Qiaoli Chen, Jiang Wang, Guoning Huang and Hong Ye*

\begin{abstract}
Background: Many studies have demonstrated the benefits of the addition of growth hormone (GH) to the controlled ovarian stimulation protocol in vitro fertilization (IVF) cycles in poor-respond patients, but the effect of $\mathrm{GH}$ on patients with poor embryonic development remain unclear. This paper was designed to investigate the efficacy of GH co-treatment during IVF for the patients with poor embryonic development.

Method: A randomized controlled trial including 158 patients with poor embryo development was conducted between July 2017 and February 2019. One hundred and seven patients were randomized for GH treatment (GH group) and 51 patients for untreated (control group). The primary end-points were the clinical pregnancy and live birth rates in the two groups. The oocyte competence were assessed through calculating the mitochondrial DNA (mtDNA) copy number in corresponding cumulus granulosa cells (CGCs). Quantitative PCR were used for calculation of mtDNA copy number.

Results: Relative to the control group, GH co-treatment resulted in a significantly higher number of retrieved oocytes $(10.29 \pm 5.92$ versus $8.16 \pm 4.17, P=0.023)$ and cleaved embryos $(6.73 \pm 4.25$ versus $5.29 \pm 3.23, P=0.036)$. The implantation rate, clinical pregnancy rates per cycle, and live birth rate per cycle were higher in the GH group than in the control group $(36.00 \%$ versus $17.86 \%, P=0.005 ; 43.93 \%$ versus $19.61 \%, P=0.005 ; 41.12 \%$ versus $17.65 \%$, $P=0.006)$. CGCs of the $\mathrm{GH}$ group had significantly higher mtDNA copy numbers than CGCs of the control group (252 versus $204, P<0.001)$.

Conclusions: These data provided further evidence to indicate that $\mathrm{GH}$ supplementation may support more live births during IVF, in patients with poor embryonic development. It also appears that oocytes generated under GH co-treatment have a better developmental competence.

(Continued on next page)
\end{abstract}

\footnotetext{
* Correspondence: yehong1210@163.com

Chongqing Key Laboratory of Human Embryo Engineering, Chongqing

Reproduction and Genetics Institute, Chongqing Health Center for Women and Children, No.64 Jin Tang Street, Yu Zhong District, Chongqing 400013, China
}

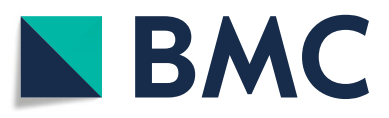

(c) The Author(s). 2020 Open Access This article is licensed under a Creative Commons Attribution 4.0 International License, which permits use, sharing, adaptation, distribution and reproduction in any medium or format, as long as you give appropriate credit to the original author(s) and the source, provide a link to the Creative Commons licence, and indicate if changes were made. The images or other third party material in this article are included in the article's Creative Commons licence, unless indicated otherwise in a credit line to the material. If material is not included in the article's Creative Commons licence and your intended use is not permitted by statutory regulation or exceeds the permitted use, you will need to obtain permission directly from the copyright holder. To view a copy of this licence, visit http://creativecommons.org/licenses/by/4.0/ The Creative Commons Public Domain Dedication waiver (http://creativecommons.org/publicdomain/zero/1.0/) applies to the data made available in this article, unless otherwise stated in a credit line to the data. 
(Continued from previous page)

Trial registration: ChiCTR1900021992 posted March 19, 2019 (retrospectively registered).

Keywords: Growth hormone, In vitro fertilization, Poor embryonic development, Oocyte competence, Mitochondrial DNA

\section{Background}

Poor embryonic development is a major cause of in vitro fertilization (IVF) failure, especially in patients with normal ovarian response. A strong association is known to exist between embryo quality and pregnancy rates $[1,2]$. In the period following fertilization, no transcription occurs in the newly formed embryo [3, 4]; thus, early embryonic development is controlled by maternally derived information until the oocyte-to-embryo transition (OET) occurs. Indeed, maternal stores of mRNAs, proteins, and mitochondria are essential for fertilization, early embryonic development, and implantation [5, 6]. Therefore, the quality of the oocytes is a key factor in determining the quality of day-3 embryos that are ready for transfer. Several factors have been investigated in relation to reductions in oocyte developmental competence, including advanced age [7], an immature cytoplasm [8], abnormal maternal protein expression [9], and insufficient mitochondria [10]. However, to date, no treatment has successfully improved the clinical outcomes in patients with poor embryonic development.

A successful outcome of IVF is largely dependent on the number and quality of oocytes retrieved during the treatment cycle. Defining oocyte quality is not straightforward, but typically, the quality and developmental potential of oocytes are evaluated via simple morphological assessment $[11,12]$. However, this evaluation cannot determine the status of predictive metabolic and mitochondrial molecular parameters [11]. Therefore, many oocytes that are defined as high quality by morphological assessment are not actually very developmentally competent, especially for implantation. In addition to morphological assessment, biochemical evaluations are necessary to accurately assess the true developmental competence of the oocyte [13-16].

Mitochondria have important roles in oocyte maturation [17], fertilization, and early embryonic development $[18,19]$. Sufficient numbers of mitochondria are necessary to support the consumption of adenosine triphosphate (ATP) that occurs during the processes of early embryonic development $[20,21]$. In humans, oocytes of women with ovarian insufficiency reportedly have lower mtDNA copy numbers than those of women with a normal ovarian profile [22], and unfertilized oocytes have lower mtDNA copy numbers compared to fertilized oocytes [18]. However, directly assessing the mtDNA copy number is not feasible, because it results in destruction of the oocyte. Examination of the cumulus granulosa cells (CGCs) that surround the oocyte is an effective alternative to the direct evaluation of oocytes [13, $14,16,23,24]$, because the mtDNA copy number in CGCs correlates with embryo quality and implantation in IVF procedures [23, 24]. Consequently, assessment of the mtDNA content of CGCs provide a promising means of assessing oocyte developmental competence.

Growth hormone (GH; an anabolic peptide hormone) is an important regulator of ovarian steroidogenesis [25], follicular development [26] and oocyte maturation [27]. The physiological effect of GH on the oocyte and folliculogenesis is presumed to be via insulin-like growth factor 1 (IGF-1) or by a direct action of GH. GH can stimulate serum and follicular IGF-1 [28]. Thus, the rationale of GH supplemented into controlled ovarian stimulation protocol is that the follicular fluid IGF-1 concentrations of women undergoing IVF is directly correlated to the number of developing follicles [29]. In addition, follicular concentrations of GH have been shown displayed a positive correlation to oocyte competence, including fertilization, embryonic development, embryo implantation, and clinical pregnancy [30,31]. In animal models, GH can improve oocyte cytoplasmic and nuclear maturation [32]. If these physiological effects were applicable within an IVF population, it may be expected to lead to the increased recruitment of matured oocytes, and the improvement of oocyte developmental competence.

Supplementation with GH has been used as an IVF adjuvant therapy for decades, especially in patients with poor ovarian response (POR) [33-36]. Recently, several studies have found that adjuvant treatment of women with GH during controlled ovarian stimulation increases the number of oocytes collected, the embryo quality and the clinical pregnancy rate compared with untreated women [35-38]. These GH-mediated improvements may be related to the elevation of mitochondrial activity in the oocyte. Results from mechanistic studies have shown that GH can improve mitochondrial function of oocytes in patients with POR, in older women and in mice [39, 40], thereby increasing numbers of oocytes collected and embryo quality.

To date, only a few trials including observational and randomized controlled trials (RCTs), have been conducted to investigate the effects of GH on IVF treatment. A Hazout et al. demonstrated GH improved the number of oocytes collected and embryos obtained [37]. 
Meta-analysis found that $\mathrm{GH}$ increased the live birth rate in patients with POR [41, 42]. Recently, several studies found that GH promoted pregnancy rate or live birth rate by reducing miscarriage rates in POR patients $[43,44]$. On the contrary, numerous other studies demonstrated that $\mathrm{GH}$ has no clear positive effect on pregnancy or live birth outcomes [45-47]. Most of the research on the effects of $\mathrm{GH}$ has focused on the treatment of POR, however, the effects of GH on patients with poor embryonic development remain unclear.

In this study, we performed an RCT to assess the effect of GH supplementation in IVF/ICSI patients with poor embryonic development. To determine whether this GH supplementation improved oocyte developmental competence, CGC mtDNA copy numbers were compared between patients with and without GH treatment.

\section{Methods}

\section{Study period and participants}

This randomized, prospective study was registered retrospectively at ChiCTR (\#1900021992), and conducted at the IVF centre of Chongqing Maternal and Child Health Care Hospital, Chongqing, China. We recruited patients in the study between July 2017 and February 2019 (Fig. 1).
Randomization was carried out by computer, and female patients were assigned to the $\mathrm{GH}$ and control groups at a proportion of 2:1. The patients and doctors could not be blinded to the allocation because there was no placebo treatment for the control group, but the embryologists who graded the embryos were blinded. For clinical followup of the IVF outcome, serum concentrations of human chorionic gonadotropin (hCG) were measured 14 days after embryo transfer (ET). Clinical pregnancy was confirmed by the presence of a gestational sac in ultrasonographic examination at week 4. Pregnancy loss within 12 weeks was defined as early miscarriage. Pregnancy after early miscarriage was defined as ongoing pregnancy. Live birth rate was defined as the number of achieved live births after 28 weeks' gestation.

Patients were recruited according to the following inclusion criteria: (1) at least one previous IVF cycle failure with no top-quality embryos (grade 1 or 2); (2) folliclestimulating hormone (FSH), luteinizing hormone (LH), and oestradiol (E2) concentrations in the normal range during the early follicular phase; (3) aged 20-45-years old [48]; unexplained infertility with normal spermatozoa before IVF or subnormal spermatozoa justifying ICSI; (5) a normal uterine cavity with regular

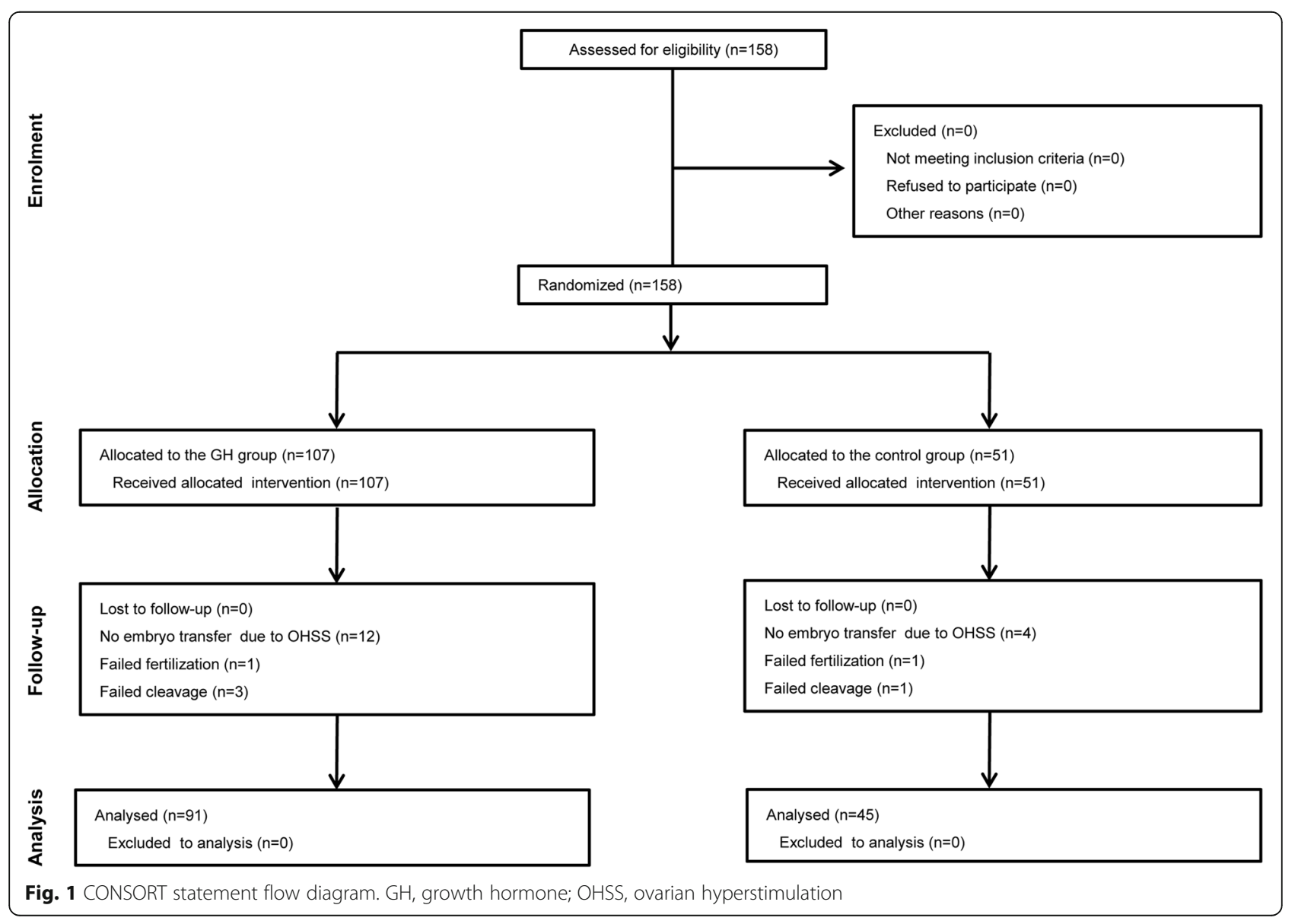


spontaneous menstrual cycles of 25-30 days; and [48] body mass index (BMI) $<25 \mathrm{~kg} / \mathrm{m}^{2}$. The exclusion criteria were (1) any genetic disease; (2) polycystic ovarian syndrome (PCOS) or endometriosis; (3) azoospermia in the male partner; and [48] a history of endocrine disorders.

\section{Clinical management}

Two ovarian-stimulation protocols were used: the gonadotropin-releasing hormone $(\mathrm{GnRH})$ long agonist protocol and the GnRH antagonist protocols. The stimulation protocol was decided according to individual patient characteristics. Gonadotropins were prescribed at the discretion of the physicians in accordance with the results of ovarian-reserve tests (anti-Müllerian hormone, antral follicular count, basal FSH) and age. The dosage was then adjusted according to follicular growth until the day of administration of hCG.

The long protocol was performed as described previously [49]. Briefly, after downregulation with a GnRH agonist (triptorelin acetate, Ipsen Pharma, Paris, France), the ovaries were stimulated with gonadotropins. For the antagonist protocol, patients were stimulated with recombinant FSH using specific dosage algorithms.

Patients in the GH group received 3 IU recombinant human GH (Jintropin AQ, Gensci, Changchun, China) per day, from the initial day of downregulation for the long protocol or stimulation for the antagonist protocol until the day of the hCG trigger. The average duration of $\mathrm{GH}$ co-treatment was 25 days for patients receiving the long agonist protocol and 10 days for those receiving the antagonist protocol.

hCG (Ovidrel, Merck Serono, Switzerland) was administered when at least three follicles measured $>18 \mathrm{~mm}$ in diameter. Transvaginal oocyte retrieval was performed $36 \mathrm{~h}$ after hCG injection, and ET was performed on day 3 after oocyte retrieval.

\section{Isolation of oocytes and cumulus cells}

Oocyte-cumulus complexes (OCCs) were retrieved $36 \mathrm{~h}$ after treatment with hCG and washed in multiple dishes with Flushing medium (OrigioFrance, Limonest, France) to eliminate the remaining mural granulosa cells, blood cells and cellular debris. The OCCs were subsequently cultured in G-IVF medium (Vitrolife, Kungsbacka, Sweden) for 2-3 h. For each OCCs, the CGCs were individually removed from OCCs via fine needles and gently pipetted with a $125-\mu \mathrm{m}$-diameter stripper pipette. CGCs were recovered in $500 \mu \mathrm{l}$ of physiological serum and centrifuged at $10000 \mathrm{~g}$ for $5 \mathrm{~min}$. The supernatant was removed, and the CGC pellets were immediately frozen at $-80^{\circ} \mathrm{C}$ until they were processed for DNA extraction.

\section{DNA extraction}

Total DNA extraction from isolated CGCs was carried out using the AllPrep DNA/RNA Micro Kit (Qiagen, Germantown, MD, USA) according to the manufacturer's recommendations. Briefly, CGCs were first lysed and homogenized in a highly denaturing guanidineisothiocyanate-containing buffer, which immediately inactivated DNases and RNases, to ensure the isolation of intact DNA and RNA. The lysate was then passed through an AllPrep DNA spin column. This column, in combination with the high-salt buffer, selectively and efficiently bound genomic DNA. The column was washed, and pure, ready-to-use DNA was eluted in $60 \mu \mathrm{l}$ of water.

\section{Quantification of mtDNA}

The mean mtDNA copy number in CGCs was determined by real-time quantitative PCR (Q-PCR) using SYBR green DNA intercalator and the CFX Connect system (Bio-Rad, Hercules, CA, USA). Primers were obtained from the Human Mitochondrial DNA (mtDNA) Monitoring Primer Set (Takara, Kusatsu, Japan). Briefly, two primer pairs (ND1 and ND5) were used for the detection of mtDNA and two primer pairs (SLCO2B1 and SERPINA1) for the detection of nuclear DNA. The mtDNA copy number was calculated twice, by determining the ratios for the ND1/SLCO2B1 pair and ND5/SERPINA1 pair. The final mtDNA copy number was determined as the average of these two calculated values.

\section{Embryo culture and assessment}

For IVF procedures, oocytes were inseminated with motile spermatozoa at a concentration of 10,000 per ml. For ICSI, oocytes were microinjected with sperm $4-6 \mathrm{~h}$ after oocyte retrieval. The fertilized oocytes were transferred into pre-equilibrated culture dishes (Thermo Scientific, Waltham, MA, USA) with $25 \mu \mathrm{l}$ of culture medium (Vitrolife Sweden, Gothenburg, Sweden) covered with $1.2 \mathrm{ml}$ of paraffin oil (Vitrolife Sweden). The embryos were cultured in an incubator $(\mathrm{MCO}-5 \mathrm{M}$, Sanyo, Osaka, Japan) at $37^{\circ} \mathrm{C}$ with $5 \% \mathrm{O}_{2}$ and $6 \% \mathrm{CO}_{2}$ until ET on day 3.

Embryo morphology was assessed according to the guidelines of the European Society of Human Reproduction and Embryology/Alpha consensus [50]. Embryos were graded according to blastomere number, blastomere size, and degree of fragmentation, using a morphological scoring system, accounting for the regularity of the blastomeres, degree of fragmentation, and microscopic appearance of the embryos. Transferable embryos were defined by the presence of 6-10 symmetrical blastomeres and $<20 \%$ fragmentation, with no multinucleation, on day 3 . 
Sample-size determination and statistical analysis

The primary outcome was the clinical pregnancy rate, and in the pre-trial period, clinical pregnancy rates were approximately 20 and $41 \%$ in untreated and GH-treated women, respectively. The difference between these rates was used for sample-size calculation, which, with $70 \%$ power and a group-size ratio of 1:2, indicated that 99 and 50 patients were needed in the $\mathrm{GH}$ and control groups, respectively.

Continuous variables are presented as the mean \pm standard deviation. Categorical variables are presented as $n(\%)$. For comparisons between the groups, $x^{2}$ test exact test was used for dichotomous variables, and the Student's $t$ test was used for continuous variables. For main variables, 95\% confidence intervals (CIs) were determined for the mean difference (MD) and relative risk (RR) in the estimates. A $P$-value $<0.05$ was considered significant. All statistical tests were performed using SAS software version 9.3 (SAS Institute, Cary, NC, USA) and SPSS software version 22, 2013 (SPSS, Chicago, IL, USA).

\section{Results}

Overview of patient characteristics and ovarian response The flow chart for patient recruitment in this study is shown in Fig. 1. We recruited 158 patients and randomized them into GH $(n=107)$ and control $(n=51)$ groups after recruitment between July 2017 and February 2019. None of the patients was lost to follow-up. In the two groups, two cases and four cases were canceled because of fertilization and cleavage failure, due to low numbers of retrieved oocytes. There were 16 cases without embryo transfer in the two groups, all due to ovarian hyperstimulation.

Patient characteristics are presented in Table 1. No significant differences were found between the two groups in terms of age, infertility duration, BMI, AMH, day 3 serum levels of FSH, LH, E2, and progesterone (P), duration of stimulation, total gonadotropin dose, or endometrial thickness.

\section{Comparison of embryological and clinical data between the $\mathrm{GH}$ and control groups}

Relative to the control group, the GH group had a significantly higher number of retrieved oocytes, number of metaphase II (MII) oocytes, number of 2PN fertilized oocytes, and number of cleaved embryos on day 2 (Table 2). Although the GH group also had a slightly higher number of transferable embryos than the control group, this difference was not statistically significant (Table 2).

There was no significant difference between GH and control group with regard to the fertilization rate, cleavage rate, transferable embryo rate, cycles reaching ET rate and number of transferred embryos per ET (Table 2). However, The GH group had significantly improved clinical outcomes relative to the control group, including implantation rate, clinical pregnancy rate, ongoing pregnancy rate, live birth rate per cycle start or per ET (Table 3). The relative risk (95\% confidence interval) was 2.324 (1.2994.158) for the clinical pregnancy rate per ET and 2.418 (1.298-4.502) for the live birth rate per ET, indicating a significant effect for using GH. Furthermore, the significantly higher ongoing pregnancy rate and live birth rate in both fresh and frozen cycles in GH group were also detected. No adverse events were associated with the use of GH in this study.

\section{Comparisons of CGC mtDNA copy number}

mtDNA was quantified from a total of 1430 CGCs that were obtained from the 158 female participants. The

Table 1 Comparisons of baseline characteristics of female participants in the growth-hormone (GH)-treated and control groups

\begin{tabular}{lll}
\hline & $\mathrm{GH}(n=107)$ & Control $(n=51)$ \\
\hline Age (years) & $32.96 \pm 4.67$ & $32.86 \pm 4.32$ \\
Infertility (years) & $6.21 \pm 3.77$ & $6.35 \pm 4.64$ \\
Body mass index $\left(\mathrm{kg} / \mathrm{m}^{2}\right)$ & $22.09 \pm 2.71$ & $21.93 \pm 2.66$ \\
Anti-Mullerian hormone $(\mathrm{ng} / \mathrm{ml})$ & $2.61 \pm 2.05$ & $2.38 \pm 2.03$ \\
Follicle-stimulating hormone $(\mathrm{mlU} / \mathrm{ml})$ & $5.79 \pm 2.46$ & $6.09 \pm 2.33$ \\
Luteinizing hormone $(\mathrm{mlU} / \mathrm{ml})$ & $2.99 \pm 1.36$ & $3.13 \pm 1.88$ \\
Oestradiol $(\mathrm{pg} / \mathrm{ml})$ & $33.69 \pm 16.20$ & $33.55 \pm 20.08$ \\
Progesterone $(\mathrm{mlU} / \mathrm{ml})$ & $0.31 \pm 0.16$ & $0.31 \pm 0.14$ \\
Days of gonadotropins (days) & $10.11 \pm 1.42$ & $10.45 \pm 1.94$ \\
Total gonadotropin dose $(\mathrm{IU})$ & $2402.14 \pm 648.33$ & $2604.41 \pm 853.42$ \\
Endometrial thickness $(\mathrm{mm})$ & $9.62 \pm 1.88$ & $9.97 \pm 1.92$ \\
Stimulation protocols & & $11 / 51(21.57 \%)$ \\
$\quad$ Antagonist & $27 / 107(25.23 \%)$ & $40 / 51$ (78.43\%) \\
$\quad$ Long protocol & $80 / 107(74.77 \%)$ & \\
\hline
\end{tabular}

All variables are presented as mean \pm SD. For comparisons between the groups, the Student's $t$ test was used 
Table 2 Comparison of embryology data between the growth-hormone (GH)-treated and control groups

\begin{tabular}{|c|c|c|c|c|}
\hline & $\mathrm{GH}(n=107)$ & Control $(n=51)$ & $P$-value & MD $(95 \% \mathrm{Cl})$ \\
\hline No. of oocytes retrieved per patient & $10.29 \pm 5.92$ & $8.16 \pm 4.17$ & $0.022^{\mathrm{a}}$ & $2.130(0.528-3.732)$ \\
\hline No. of metaphase II oocytes & $9.08 \pm 5.83$ & $7.49 \pm 3.98$ & $0.040^{\mathrm{a}}$ & $1.590(0.036-3.144)$ \\
\hline No. of 2PN oocytes & $6.77 \pm 4.51$ & $5.45 \pm 3.30$ & $0.049^{\mathrm{a}}$ & $1.320(0.075-2.565)$ \\
\hline Fertilization rate (\%) & $724 / 972(74.49 \%)$ & 278/382 (74.73\%) & $0.564^{b}$ & \\
\hline No. of cleaved embryos & $6.73 \pm 4.25$ & $5.29 \pm 3.23$ & $0.033^{\mathrm{a}}$ & $1.440(0.242-2.638)$ \\
\hline Cleavage rate (\%) & $693 / 724(95.72 \%)$ & $270 / 278(97.12 \%)$ & $0.397^{\mathrm{b}}$ & \\
\hline No. of transferable embryos & $3.30 \pm 2.14$ & $2.96 \pm 1.97$ & $0.400^{\mathrm{a}}$ & \\
\hline Transferable embryo rate (\%) & $340 / 693(49.06 \%)$ & $151 / 270(55.93 \%)$ & $0.065^{b}$ & \\
\hline No. of transferred embryos per ET & $1.92 \pm 0.40$ & $1.87 \pm 0.40$ & $0.464^{\mathrm{a}}$ & \\
\hline Cycles reaching ET rate (\%) & $91 / 107(85.05 \%)$ & $45 / 51(88.24 \%)$ & $0.768^{b}$ & \\
\hline \multicolumn{5}{|l|}{ Reason for lack of ET } \\
\hline OHSS, freezing of all embryos, $n$ & 12 & 4 & & \\
\hline Failed fertilization, $n$ & 1 & 1 & & \\
\hline Failed cleavage, $n$ & 3 & 1 & & \\
\hline
\end{tabular}

Categorical variables are presented as proportion (\%). Continuous variables are presented as mean \pm SD

For comparisons of dichotomous variables, $X^{2}$ test was used. For comparisons of continuous variables, Student's $t$ test was used

$\mathrm{Cl}$ confidence interval, $E T$ embryo transfer, $M D$ mean difference, OHSS ovarian hyperstimulation

Fertilization rate: No. of 2PN oocytes/ No. of metaphase II oocytes; Cleavage rate: No. of cleaved embryos/ No. of 2PN oocytes; Transferable embryo rate: No. of transferable embryos/ No. of cleaved embryos

a, Student's $t$ test; ${ }^{b}, \mathrm{X}^{2}$ test

median mtDNA copy number in the CGCs of transferable embryos derived from the control group and the two groups were both significantly higher than that of non-transferable embryos (250 versus $169, P<10^{-4}$ ) (Fig. 2a and Figure S1). Furthermore, the mtDNA copy number in CGCs was significantly higher for the simultaneous implantation of two embryos than for the nonimplanted group (262 versus $175, P<10^{-4}$ ) (Fig. 2b). Then we investigated the effect of $\mathrm{GH}$ supplementation on oocyte quality in the two patient groups (using

Table 3 Comparison of clinical data between the growth-hormone $(\mathrm{GH})$-treated and control groups

\begin{tabular}{|c|c|c|c|c|}
\hline & $\mathrm{GH}(n=107)$ & Control $(n=51)$ & $P$-value & $\mathrm{RR}(95 \% \mathrm{Cl})$ \\
\hline Implantation rate (\%) & $63 / 175(36.00 \%)$ & $15 / 84(17.86 \%)$ & 0.005 & $2.016(1.224-3.322)$ \\
\hline Clinical pregnancy rate/cycle start (\%) & $47 / 107(43.93 \%)$ & $10 / 51(19.61 \%)$ & 0.005 & $2.240(1.235-4.064)$ \\
\hline Clinical pregnancy rate/ET (\%) & $47 / 91(51.65 \%)$ & $10 / 45(22.22 \%)$ & 0.002 & $2.324(1.299-4.158)$ \\
\hline Early miscarriage rate/cycle start (\%) & $3 / 107(2.80 \%)$ & $1 / 51(2.00 \%)$ & 1 & \\
\hline Early miscarriage rate//ET (\%) & 3/91 (3.30\%) & $1 / 45(2.22 \%)$ & 1 & \\
\hline Fresh ET rate (\%) & 69/91 (75.82\%) & $37 / 45(82.22 \%)$ & 0.531 & \\
\hline Fresh ET clinical pregnancy rate (\%) & $37 / 69(53.62 \%)$ & $8 / 37(21.62 \%)$ & 0.003 & $2.480(1.293-4.758)$ \\
\hline Fresh ET ongoing pregnancy rate (\%) & $34 / 69(49.28 \%)$ & $7 / 37(18.92 \%)$ & 0.004 & \\
\hline Fresh ET live birth rate (\%) & $34 / 69(49.28 \%)$ & $7 / 37(18.92 \%)$ & 0.004 & $2.605(1.282-5.291)$ \\
\hline Frozen ET rate(\%) & 22/91 (24.18\%) & $8 / 45(17.78 \%)$ & 0.531 & \\
\hline Frozen ET clinical pregnancy rate (\%) & $10 / 22(45.45 \%)$ & $2 / 8(25.00 \%)$ & 0.555 & \\
\hline Frozen ET ongoing pregnancy rate (\%) & $10 / 22(45.45 \%)$ & $2 / 8(25.00 \%)$ & 0.555 & \\
\hline Frozen ET live birth rate (\%) & $10 / 22(45.45 \%)$ & $2 / 8(25.00 \%)$ & 0.555 & $1.818(0.503-6.569)$ \\
\hline Ongoing pregnancy rate /cycle start (\%) & $44 / 107(41.12 \%)$ & $9 / 51(17.65 \%)$ & 0.006 & \\
\hline Ongoing pregnancy rate /ET (\%) & 44/91 (48.35\%) & $9 / 45(20.00 \%)$ & 0.003 & \\
\hline Live birth rate/cycle start (\%) & $44 / 107(41.12 \%)$ & $9 / 51(17.65 \%)$ & 0.006 & $2.330(1.235-4.396)$ \\
\hline Live birth rate/ET (\%) & $44 / 91(48.35 \%)$ & $9 / 45(20.00 \%)$ & 0.003 & $2.418(1.298-4.502)$ \\
\hline
\end{tabular}

Categorical variables are presented as proportion (\%)

For comparisons of dichotomous variables, $\mathrm{X}^{2}$ test was used

$C l$ confidence interval, $E T$ embryo transfer, $R R$ relative risk 

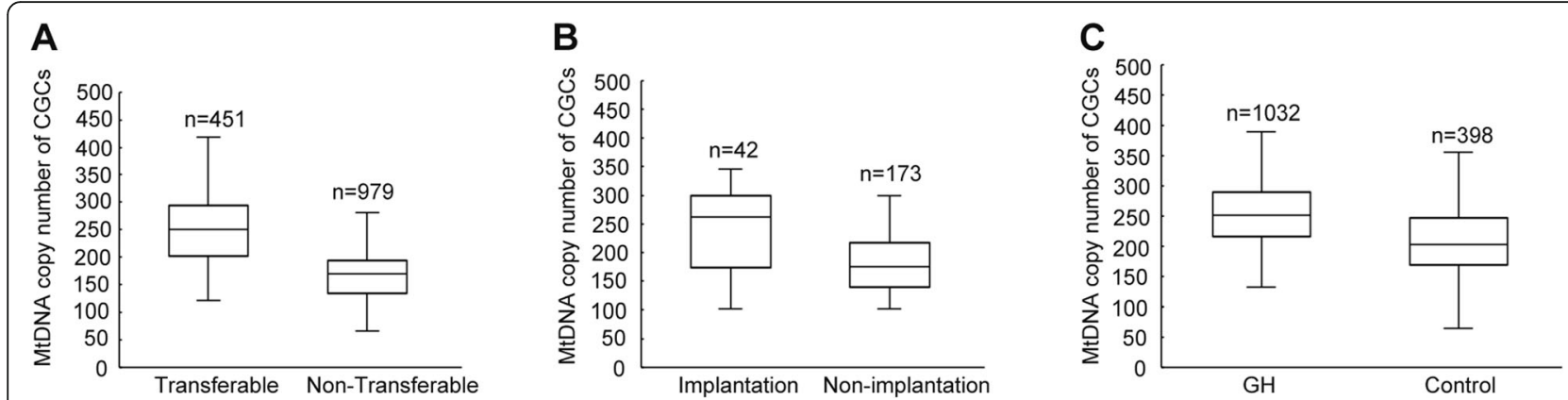

Fig. 2 The relationships between CGC mtDNA and embryo quality, implantation, and GH supplementation. a mtDNA copy number per CGC for transferable and non-transferable embryos. b mtDNA copy number per CGC for implanted and non-implanted embryos. c mtDNA copy number per CGC for the GH and control groups. CGC, cumulus granulosa cell; GH, growth hormone; mtDNA, mitochondrial DNA

mtDNA copy number as a proxy), we found a significantly higher copy number in CGCs in the GH group (252 versus 204, $P<10^{-4}$ ) (Fig. 2c), suggesting that $\mathrm{GH}$ treatment in IVF/ICSI cycles increase the mitochondrial activity in oocytes.

\section{Discussion}

GH supplementation is used as an adjuvant therapy for patients with POR or older age who undergo IVF [51]. In this study, we examined the effect of adding $\mathrm{GH}$ to the $\mathrm{GnRH}$ antagonist protocol or the $\mathrm{GnRH}$ agonist long protocol in 158 women with poor embryonic development who underwent IVF/ICSI cycles. We found that the numbers of oocytes retrieved, 2PN fertilized oocytes, and cleaved embryos on day 2 were significantly higher in the GH group than in the control group. Most importantly, we also identified increased clinical pregnancy and live birth rates in the GH group.

To the best of our knowledge, this study is the first in which the impact of GH co-treatment during IVF/ICSI cycles in women with poor embryonic development has been investigated. In our study cohort, there was no significant difference in the total gonadotropin dose or mean E2 level on the trigger day between the two groups, in contrast to previous findings [33, 38]. A possible explanation for this discrepancy is that high $\mathrm{GH}$ doses (8 IU/day and $12 \mathrm{IU} /$ day) were used in the previous two studies, whereas we used a low dose (3 IU/day) in the short-term stimulation cycle, because increasing the dose would have added substantially to the cost of the trial. We did not find a significant difference in the total number of days of gonadotropin stimulation between the two groups, whereas in a European and Australian multi-centre study of women with hypogonadotropic hypogonadism [52], GH treatment resulted in a significant dose-dependent decrease in ovarian stimulation time.

Several studies have demonstrated that adjuvant GH treatment can improve the IVF/ICSI outcome in patients with POR, via elevation of the number of oocytes (including MII oocytes) that are retrieved [33, 37, 38, 53], and in turn the fertilization rates and the numbers of transferable embryos. Our results corroborated these previous findings, demonstrating that adjuvant GH treatment in women with history of poor embryonic development increased the number of oocytes (including 2PN fertilized oocytes) that were retrieved, compared with the control group. However, although we observed a higher number of transferable embryos in the GH group than in the control group, this difference was not statistically significant. Although it is possible that, with a larger sample size, this effect might become significant, the observed difference in the number of transferable embryos was not sufficient to account for the greater than twofold increase that occurred in implantation rate, clinical pregnancy rate, and live birth rate. Thus, we speculate that $\mathrm{GH}$ supplementation improves the true developmental competence of oocytes, rather than simply increasing the number of retrieved oocytes.

Results from human and animal studies have demonstrated that GH has important roles in the processes of folliculogenesis, steroidogenesis, and oocyte maturation [54]. GH can stimulate the production of insulin-like growth factor 1 (IGF-1) in serum and follicles [28]. In animal models, IGF-1 can suppress follicular apoptosis [55]. Avoidance of apoptosis is also essential for follicular development and oocyte maturation [56]. Overall, this suggests that GH acts through IGF-1 to promote follicular development and the inhibition of follicular apoptosis. The mechanism underlying GH-mediated improvement of oocyte quality is presumed to be the elevation of oocyte mitochondrial function [39, 40, 57]. The mitochondrial activity in oocytes decreases with age [58]. During oocyte maturation, interactions with CGCs ensure that the oocytes have sufficient energyproduction reserves for meiosis and to support subsequent embryonic development. Here, we confirmed that the mtDNA content in CGCs is positively associated 
with corresponding embryo development and implantation competence, which is consistent with previous observations $[23,24]$. Therefore, we can use the mtDNA content in CGCs as a reliable biomarker for the assessment of oocyte quality.

Several studies have demonstrated that GH can improve the mitochondrial activity of oocytes. However, majority of these studies focused on the effect of GH on the older patients, and the results were from in vitro matured oocytes or animal models $[39,40,57]$. Until now, there is no research including large data of mtDNA copy number of CGCs in normal human oocytes for the assessement of the effect of GH on the oocyte quality, especially in patients with poor embryonic development. In the present study, we calculated the mtDNA copy number in total 1430 CGCs in GH and control group. The results showed that the mtDNA copy number of CGCs was significantly higher in the GH group than in the control group, suggesting that adjuvant GH treatment in IVF/ICSI cycles does indeed improve oocyte developmental competence.

The quality of the transferred embryo is a key factor in successful implantation and pregnancy, as confirmed by our results. However, we did not detect a change in the number of transferable embryos in response to $\mathrm{GH}$ treatment, possibly because improvements in features that affect the quality of the embryo, such as metabolism, ATP homeostasis, and gene expression, cannot be detected through morphological assessment. Rather, the higher quality of the transferred embryos in the $\mathrm{GH}$ group was demonstrated by the more-than-twofold improvement in the clinical pregnancy and live birth rates compared with the control group, indicating the potential benefits of GH treatment in patients with poor embryonic development.

Our study had some notable limitations. We classified patients with previous implantation failure that was mainly defined by the absence of top-grade embryos (grade 1 or 2) as patients with 'poor embryonic development' (noting that there is no standard definition for this group of patients). However, poor embryonic development in 1 cycle does not necessarily mean it will also occur in the next cycle. To address this issue, we plan to recruite only patients with three or more previous failures resulting from absence of top-grade embryos in later study, which require more than 5 years for the recruitment of a sufficient number of such participants, because these patients represent a small fraction of patients undergoing IVF. Another limitation of the study is that we were not able to assess the cumulative live birth rate, because not all patients had all of their cryopreserved embryos transferred. However, we also can demonstrate the benefits of GH treatment in IVF/ICSI cycles from the improvements in the live birth rate and mtDNA copy number of CGCs.

\section{Conclusions}

The results of this study have demonstrated that $\mathrm{GH}$ supplementation may have a positive effect on IVF outcome, including improvements in the numbers of oocytes retrieved and live birth rate, in patients with poor embryonic development. Furthermore, the increased CGC mtDNA copy number in GH group provide an indirect evidence that GH con-treatment may improve the oocyte quality and developmental competence.

\section{Supplementary information}

Supplementary information accompanies this paper at https://doi.org/10. 1186/s12884-020-03004-9.

Additional file 1: Figure S1. The relationships between CGC mtDNA and embryo quality and implantation in control group. (A) mtDNA copy number per CGC for transferable and non-transferable embryos. (B) mtDNA copy number per CGC for implanted and non-implanted embryos.

\section{Abbreviations}

GH: Growth hormone; IVF: In vitro fertilization; mtDNA: Mitochondrial DNA; CGCs: Cumulus granulosa cells; OET: Oocyte-to-embryo transition;

ATP: Adenosine triphosphate; POR: Poor ovarian response; RCT: Randomized controlled trial; hCG: Human chorionic gonadotropin; ET: Embryo transfer; FSH: Follicle-stimulating hormone; LH: Luteinizing hormone; E2: Oestradiol; BMI: Body mass index; PCOS: Polycystic ovarian syndrome;

$\mathrm{GnRH}$ : Gonadotropin-releasing hormone; OCCs: Oocyte-cumulus complexes; Cls: Confidence intervals; MD: Mean difference; RR: Relative risk;

OHSS: Ovarian hyperstimulation

\section{Acknowledgements}

Not applicable.

\section{Authors' contributions}

$J, \mathrm{GH}$ and $\mathrm{HY}$ conceived and designed the study. QC and $\mathrm{HY}$ recruited participants and managed the clinical protocols. JW collected the CGCS samples. JL performed the experiments and analyzed the data. $J L$ drafted the manuscript, and all other authors checked and amended the final manuscript. All authors read and approved the final manuscript.

\section{Funding}

This study was supported by Chongqing YuZhong Science Project (20170127) and clinical research of Chinese Medical Association (17020430712, 17020430713). The funding bodies played no role in designing the study; in collecting, analyzing, or interpreting data; or in writing the manuscript.

\section{Availability of data and materials}

The datasets used and analyzed in the current study are available from the corresponding author on reasonable request.

\section{Ethics approval and consent to participate}

This study was approved by the Institutional Review Board (IRB) of Chongqing Health Center for Women and Children. In accordance with the measures of the People's Republic of China on the administration of Human Assisted Reproductive Technology, the ethical principles of the Human Assisted Reproductive Technology as well as the Helsinki declaration. In addition, written and informed consent was obtained from each participant that accepted the use of adjuvants, and they were required to pay for these adjuvants over and above the IVF treatment charges.

Consent for publication

Not applicable.

Competing interests

The authors declare that they have no conflict of interests. 


\section{Received: 31 January 2020 Accepted: 8 May 2020}

\section{Published online: 20 May 2020}

\section{References}

1. Oron G, Son WY, Buckett W, Tulandi T, Holzer H. The association between embryo quality and perinatal outcome of singletons born after single embryo transfers: a pilot study. Hum Reprod. 2014;29(7):1444-51.

2. Zhu J, Lian Y, Li M, Chen L, Liu P, Qiao J. Does IVF cleavage stage embryo quality affect pregnancy complications and neonatal outcomes in singleton gestations after double embryo transfers? J Assist Reprod Genet. 2014; 31(12):1635-41.

3. Yan L, Yang M, Guo H, Yang L, Wu J, Li R, et al. Single-cell RNA-Seq profiling of human preimplantation embryos and embryonic stem cells. Nat Struct Mol Biol. 2013;20(9):1131-9.

4. Xue Z, Huang $K$, Cai $C$, Cai L, Jiang CY, Feng $Y$, et al. Genetic programs in human and mouse early embryos revealed by single-cell RNA sequencing. Nature. 2013;500(7464):593-7.

5. Gosden RG. Oogenesis as a foundation for embryogenesis. Mol Cell Endocrinol. 2002;186(2):149-53.

6. Swain JE, Pool TB. ART failure: oocyte contributions to unsuccessful fertilization. Hum Reprod Update. 2008;14(5):431-46.

7. Faddy MJ. Follicle dynamics during ovarian ageing. Mol Cell Endocrinol. 2000;163(1-2):43-8.

8. Watson AJ. Oocyte cytoplasmic maturation: a key mediator of oocyte and embryo developmental competence. J Anim Sci. 2007;85(13 Suppl):E1-3.

9. Wang $S$, Kou Z, Jing Z, Zhang Y, Guo X, Dong $M$, et al. Proteome of mouse oocytes at different developmental stages. Proc Natl Acad Sci U S A. 2010; 107(41):17639-44

10. Babayev E, Seli E. Oocyte mitochondrial function and reproduction. Curr Opin Obstet Gynecol. 2015;27(3):175-81.

11. Rienzi L, Vajta G, Ubaldi F. Predictive value of oocyte morphology in human IVF: a systematic review of the literature. Hum Reprod Update. 2011;17(1): 34-45.

12. Balaban B, Urman B. Effect of oocyte morphology on embryo development and implantation. Reprod BioMed Online. 2006;12(5):608-15.

13. Fragouli $E$, Wells $D$, lager AE, Kayisli UA, Patrizio P. Alteration of gene expression in human cumulus cells as a potential indicator of oocyte aneuploidy. Hum Reprod. 2012;27(8):2559-68.

14. Ekart J, McNatty K, Hutton J, Pitman J. Ranking and selection of MII oocytes in human ICSI cycles using gene expression levels from associated cumulus cells. Hum Reprod. 2013;28(11):2930-42.

15. lager $A E$, Kocabas $A M$, Otu HH, Ruppel $P$, Langerveld $A$, Schnarr $P$, et al. Identification of a novel gene set in human cumulus cells predictive of an oocyte's pregnancy potential. Fertil Steril. 2013;99(3):745-52 e6.

16. Magli MC, Albanese C, Crippa A, Tabanelli C, Ferraretti AP, Gianaroli L. Deoxyribonucleic acid detection in blastocoelic fluid: a new predictor of embryo ploidy and viable pregnancy. Fertil Steril. 2018;111:77-85.

17. Bentov Y, Yavorska T, Esfandiari N, Jurisicova A, Casper RF. The contribution of mitochondrial function to reproductive aging. J Assist Reprod Genet. 2011;28(9):773-83.

18. Santos TA, El Shourbagy S, St John JC. Mitochondrial content reflects oocyte variability and fertilization outcome. Fertil Steril. 2006;85(3):584-91.

19. Reynier P, May-Panloup P, Chretien MF, Morgan CJ, Jean M, Savagner F et al. Mitochondrial DNA content affects the fertilizability of human oocytes. Mol Hum Reprod. 2001;7(5):425-9.

20. Ge H, Tollner TL, Hu Z, Dai M, Li X, Guan H, et al. The importance of mitochondrial metabolic activity and mitochondrial DNA replication during oocyte maturation in vitro on oocyte quality and subsequent embryo developmental competence. Mol Reprod Dev. 2012;79(6):392-401.

21. Van Blerkom J, Davis PW, Lee J. ATP content of human oocytes and developmental potential and outcome after in-vitro fertilization and embryo transfer. Hum Reprod. 1995:10(2):415-24.

22. May-Panloup P, Chretien MF, Jacques C, Vasseur C, Malthiery $Y$, Reynier P. Low oocyte mitochondrial DNA content in ovarian insufficiency. Hum Reprod. 2005;20(3):593-7.

23. Ogino M, Tsubamoto $H$, Sakata K, Oohama N, Hayakawa H, Kojima T, et al. Mitochondrial DNA copy number in cumulus cells is a strong predictor of obtaining good-quality embryos after IVF. J Assist Reprod Genet. 2016;33(3): $367-71$.
24. Taugourdeau A, Desquiret-Dumas V, Hamel JF, Chupin S, Boucret L, FerreL'hotellier $V$, et al. The mitochondrial DNA content of cumulus cells may help predict embryo implantation. J Assist Reprod Genet. 2018;36:223-8.

25. Nakamura E, Otsuka F, Inagaki K, Miyoshi T, Matsumoto Y, Ogura K, et al. Mutual regulation of growth hormone and bone morphogenetic protein system in steroidogenesis by rat granulosa cells. Endocrinology. 2012;153(1): 469-80.

26. Bachelot A, Monget P, Imbert-Bollore P, Coshigano K, Kopchick JJ, Kelly PA, et al. Growth hormone is required for ovarian follicular growth Endocrinology. 2002;143(10):4104-12.

27. Bevers MM, Izadyar F. Role of growth hormone and growth hormone receptor in oocyte maturation. Mol Cell Endocrinol. 2002;197(1-2):173-8.

28. Pellegrini S, Fuzzi B, Pratesi S, Mannelli M, Criscuoli L, Messeri G, et al. In-vivo studies on ovarian insulin-like growth factor I concentrations in human preovulatory follicles and human ovarian circulation. Hum Reprod. 1995; 10(6):1341-5.

29. Oosterhuis GJ, Vermes I, Lambalk CB, Michgelsen HW, Schoemaker J. Insulinlike growth factor (IGF)-I and IGF binding protein-3 concentrations in fluid from human stimulated follicles. Hum Reprod. 1998:13(2):285-9.

30. Mendoza C, Ruiz-Requena E, Ortega E, Cremades N, Martinez F, Bernabeu R, et al. Follicular fluid markers of oocyte developmental potential. Hum Reprod. 2002;17(4):1017-22.

31. Mendoza C, Cremades N, Ruiz-Requena E, Martinez F, Ortega E, Bernabeu S, et al. Relationship between fertilization results after intracytoplasmic sperm injection, and intrafollicular steroid, pituitary hormone and cytokine concentrations. Hum Reprod. 1999;14(3):628-35.

32. Izadyar F, Zhao J, Van Tol HT, Colenbrander B, Bevers MM. Messenger RNA expression and protein localization of growth hormone in bovine ovarian tissue and in cumulus oocyte complexes (COCs) during in vitro maturation. Mol Reprod Dev. 1999:53(4):398-406.

33. Kucuk T, Kozinoglu H, Kaba A. Growth hormone co-treatment within a GnRH agonist long protocol in patients with poor ovarian response: a prospective, randomized, clinical trial. J Assist Reprod Genet. 2008;25(4):123-7.

34. Yovich JL, Stanger JD. Growth hormone supplementation improves implantation and pregnancy productivity rates for poor-prognosis patients undertaking IVF. Reprod BioMed Online. 2010;21(1):37-49.

35. Keane KN, Yovich JL, Hamidi A, Hinchliffe PM, Dhaliwal SS. Single-Centre retrospective analysis of growth hormone supplementation in IVF patients classified as poor-prognosis. BMJ Open. 2017;7(10):e018107.

36. Keane KN, Hinchliffe PM, Rowlands PK, Borude G, Srinivasan S, Dhaliwal SS, et al. DHEA supplementation confers no additional benefit to that of growth hormone on pregnancy and live birth rates in IVF patients categorized as poor prognosis. Front Endocrinol. 2018;9:14.

37. Hazout A, Junca A, Menezo Y, Demouzon J, Cohen-Bacrie P. Effect of growth hormone on oocyte competence in patients with multiple IVF failures. Reprod BioMed Online. 2009;18(5):664-70.

38. Bassiouny YA, Dakhly DMR, Bayoumi YA, Hashish NM. Does the addition of growth hormone to the in vitro fertilization/intracytoplasmic sperm injection antagonist protocol improve outcomes in poor responders? A randomized, controlled trial. Fertil Steril. 2016;105(3):697-702.

39. Weall BM, Al-Samerria S, Conceicao J, Yovich لL, Almahbobi G. A direct action for $\mathrm{GH}$ in improvement of oocyte quality in poor-responder patients. Reproduction. 2015:149(2):147-54

40. Hou HY, Wang X, Yu Q, Li HY, Li SJ, Tang RY, et al. Evidence that growth hormone can improve mitochondrial function in oocytes from aged mice. Reproduction. 2018;157(4):345-58.

41. Kolibianakis EM, Venetis CA, Diedrich K, Tarlatzis BC, Griesinger G. Addition of growth hormone to gonadotrophins in ovarian stimulation of poor responders treated by in-vitro fertilization: a systematic review and metaanalysis. Hum Reprod Update. 2009;15(6):613-22.

42. Duffy JM, Ahmad G, Mohiyiddeen L, Nardo LG, Watson A. Growth hormone for in vitro fertilization. Cochrane Database Syst Rev. 2010;1:CD000099.

43. Jeve YB, Bhandari HM. Effective treatment protocol for poor ovarian response: a systematic review and meta-analysis. J Hum Reprod Sci. 2016; 9(2):70-81.

44. Lattes K, Brassesco M, Gomez M, Checa MA. Low-dose growth hormone supplementation increases clinical pregnancy rate in poor responders undergoing in vitro fertilisation. Gynecol Endocrinol. 2015:31(7):565-8.

45. Yu X, Ruan J, He LP, Hu W, Xu Q, Tang J, et al. Efficacy of growth hormone supplementation with gonadotrophins in vitro fertilization for poor ovarian responders: an updated meta-analysis. Int J Clin Exp Med. 2015;8(4):4954-67. 
46. Eftekhar M, Aflatoonian A, Mohammadian F, Eftekhar T. Adjuvant growth hormone therapy in antagonist protocol in poor responders undergoing assisted reproductive technology. Arch Gynecol Obstet. 2013;287(5):101721.

47. Suikkari A, MacLachlan V, Koistinen R, Seppala M, Healy D. Double-blind placebo controlled study: human biosynthetic growth hormone for assisted reproductive technology. Fertil Steril. 1996;65(4):800-5.

48. Ma H, O'Neil RC, Marti Gutierrez N, Hariharan M, Zhang ZZ, He Y, et al. Functional human oocytes generated by transfer of polar body genomes. Cell Stem Cell. 2017;20(1):112-9.

49. Xiong S, Han W, Liu JX, Zhang XD, Liu WW, Liu H, et al. Effects of cumulus cells removal after $6 \mathrm{~h}$ co-incubation of gametes on the outcomes of human IVF. J Assist Reprod Genet. 2011;28(12):1205-11.

50. Alpha Scientists in Reproductive M, Embryology ESIGo. The Istanbul consensus workshop on embryo assessment: proceedings of an expert meeting. Hum Reprod. 2011;26(6):1270-83.

51. Hart RJ, Rombauts L, Norman RJ. Growth hormone in IVF cycles: any hope? Curr Opin Obstet Gynecol. 2017;29(3):119-25.

52. Jacobs $H S$, Shoham Z, Schachter M, Braat $D D$, Hamiltongairley $D$, Gillingsmith CM, Hull MG, Burger HG, Healy DL, Coutts JR, Fleming R. Cotreatment with growth hormone and gonadotropin for ovulation induction in hypogonadotropic patients: a prospective, randomized placebo-controlled, dose-response study. European and Australian Multicenter Study. Fertil Steril. 1995;64(5):917-23.

53. Du XF, Yang XH, Li J, Hao M, Guo YH. Growth hormone co-treatment within a GnRH agonist long protocol improves implantation and pregnancy rates in patients undergoing IVF-ET. Arch Gynecol Obstet. 2016;294(4):877-83.

54. de Prada JK, VandeVoort CA. Growth hormone and in vitro maturation of rhesus macaque oocytes and subsequent embryo development. J Assist Reprod Genet. 2008;25(4):145-58.

55. Chun SY, Billig H, Tilly JL, Furuta I, Tsafriri A, Hsueh AJ. Gonadotropin suppression of apoptosis in cultured preovulatory follicles: mediatory role of endogenous insulin-like growth factor I. Endocrinology. 1994;135(5):184553.

56. Baker J, Hardy MP, Zhou J, Bondy C, Lupu F, Bellve AR, et al. Effects of an Igf1 gene null mutation on mouse reproduction. Mol Endocrinol. 1996;10(7): 903-18.

57. Regan SLP, Knight PG, Yovich JL, Arfuso F, Dharmarajan A. Growth hormone during in vitro fertilization in older women modulates the density of receptors in granulosa cells, with improved pregnancy outcomes. Fertil Steril. 2018;110(7):1298-310.

58. Fragouli E, Spath K, Alfarawati S, Kaper F, Craig A, Michel CE, et al. Altered levels of mitochondrial DNA are associated with female age, aneuploidy, and provide an independent measure of embryonic implantation potential. PLoS Genet. 2015;11(6):e1005241.

\section{Publisher's Note}

Springer Nature remains neutral with regard to jurisdictional claims in published maps and institutional affiliations.

Ready to submit your research? Choose BMC and benefit from:

- fast, convenient online submission

- thorough peer review by experienced researchers in your field

- rapid publication on acceptance

- support for research data, including large and complex data types

- gold Open Access which fosters wider collaboration and increased citations

- maximum visibility for your research: over $100 \mathrm{M}$ website views per year

At BMC, research is always in progress.

Learn more biomedcentral.com/submissions 